\title{
Effect of Sandplay Therapy on \\ Study Stress and Academic \\ Self-Efficacy of Korean-Chinese Children*
}

\author{
Song, Yeo Ho Soo $\mathrm{Ah}^{* *}$
}

\begin{abstract}
$<$ Abstract $>$
Korean-Chinese children living in China have to face the environment containing early education and admission examinations due to increasingly overheated education fever. As a result, many children suffer academic stress, psychological conflicts and maladaptive problem behaviors. Studies about these social and cultural phenomenons are ongoing and the need for psychological approach is increasing. Therefore, in this study, we will find out if sandplay therapy is effective in reducing academic stress of Korean-Chinese children in China and improving their academic self-efficiency. This study is total 8 sessions and conducted to 24 children. The results obtained from this study are as follows. The result shows that sandplay therapy is effective in reducing the academic stress of Korean-Chinese children and promoting their academic self-efficiency. Through the qualitative analysis of sand scenes, we can see characteristics of sand scenes and psychological characteristics of Korean-Chinese children.
\end{abstract}

Keywords : Sandplay Therapy, Academic Stress, Academic Self-efficiency

\footnotetext{
* This thesis was written for a 2019 master's program at the Namseoul University.
}

** Therapist, Mara Child \& Family Counseling Center (kijungnet10@naver.com) 
Journal of Symbols \& Sandplay Therapy, Vol.10 No.2.

\section{I . Introduction}

China is a country of 1.4 billion people where all things begin and end with competition. To survive in such an environment, children concentrate in their studies while adults strive for good employment. As reported by the Yanbian Daily, the Korean-Chinese community in China demonstrates the highest level of passion for education and is setting a standard for ethnic education (Kim, 2018). As social demand and competition continues to bolster educational fervor within the community, adolescents experience psychological and emotional stress, in particular as they struggle to get into college. Younger children also go through similar difficulties as they endure an educational system that places importance on getting into a prestigious junior high school.

Elementary school students in Korean-Chinese communities are often subject to certain social expectations regarding education and what junior high school they get admitted to. What must be emphasized here is that these children are at an important stage of life where they should be more focused on learning social skills and developing a sound perception of and expectations for the society. However, many of these children find themselves going to tutoring classes and other types of private education after school, signed up for them by their parents. This type of educational fervor drives children as early as in kindergarten to study ahead of their age, and elementary school students have no choice but to pre-learn, learn and review what they have learned as a daily routine (Kim, 2018). This has led many children to experience academic stress and psychological conflict, with some demonstrating maladaptive behaviors.

Analyses show that the main source of stress for young students comes from school, largely academic factors (Um, 2013). The burden of studying and getting good grades was found to be the main reason behind childhood stress and different levels of stress (Kim, 2003). Most children lack the level of intelligence or linguistic development needed to perceive the reason for stress and respond accordingly. This leads to an accumulation of stress, which in turn may cause physical illness and maladaptive behaviors or symptoms such as aggressiveness, anxiety, depression and low self-esteem (Kim, 2005). 
As in Korea, a social obsession over education in the Korean-Chinese community may also affect the academic self-efficiency of children by interfering with their academic achievement. Stress impacts academic self-concept and self-efficiency. Excessive academic stress may thus precipitate negative emotions such as lack of confidence, anxiety, anguish and withdrawal. It is manifested in the form of low self-concept and takes a toll on academic self-efficiency (Um, 2013).

Academic self-efficiency is defined as one's belief in his or her ability to successfully accomplish certain academic tasks (Bandura, 1997). Those with higher academic self-efficiency tend to show higher levels of commitment in addressing stress and seeking social support, while the level of aggressive response is lower (Kim, 2017). According to a study by Ae-kyoung Lee (2009) that looks into the relationship between academic stress and academic self-efficiency of high school students, students with higher levels of self-efficiency demonstrated lower levels of academic stress in all categories compared to students with lower levels of self-efficiency, suggesting that students with high levels of self-efficiency are not as vulnerable to stress.

Sub-factors of academic self-efficiency demonstrate significant negative correlation with sub-factors of academic stress (Ko, 2012). A cognitive and behavioral training program designed to address academic stress and text anxiety by applying different methods to improve school adaptability and academic enthusiasm confirmed that providing specific study tips to children are effective in reducing academic stress (Shin \& Jung, 2006). There were also some partial effects on cognition, emotional learning and anxiety related to school assignments and exams.

In this study, sandplay therapy was performed on a number of Korean-Chinese children living in China with an objective to relieve academic stress and enhance academic self-efficiency. While there are many different kinds of psychotherapy interventions that produce positive effects on children, sandplay therapy is suitable for Korean-Chinese children in China considering their linguistic and cultural characteristics. Sandplay is an effective therapy approach for children who have difficulty articulating their emotions and thoughts with words. It enables subjects to express themselves in silence, liberating them from words and reason that put too much weight on value and meaning (Steinhardt, 2013). During sandplay therapy, a client and 
Journal of Symbols \& Sandplay Therapy, Vol.10 No.2.

the therapist encounter the positive experience of becoming one in a safe environment. It is a type of psychotherapy that allows clients to develop self-healing capabilities. By playing with various figures on a sand tray and expressing their emotions throughout the process, the client becomes conscious of the unconsciousness (Lee et al., 2016). The ultimate objective of sandplay therapy is to heal psychological hardships, but it goes further by bringing the inner world of the client and the surrounding natural and cultural worlds together in peaceful balance and harmony (Steinhardt, 2013).

Thus far, no studies have been made on the effect of sandplay therapy on levels of academic stress and academic self-efficiency of Korean-Chinese children in China. In this study, sandplay therapy was performed on Korean-Chinese children living in China to look into the effects of sandplay therapy on levels of academic stress and academic self-efficiency of these children.

The study examines the following research questions:

1. Is sandplay therapy effective in reducing academic stress of Korean-Chinese children living in China?

2. Is sandplay therapy effective in improving academic self-efficiency of Korean-Chinese children living in China?

\section{Research Method}

\section{Participants}

48 Korean-Chinese children from two elementary schools located in the Korean-Chinese self-governing province of Yanji and children of members from the Yanbian Education Research Society who attend elementary school were chosen to participate in the study. They were recommended by their homeroom teachers and parents. The participants were divided evenly into two groups, Group 1 and Group 2, with 24 participants in each group. Group 1 was the experimental group. Two sandplay therapy sessions were performed each week for each of the 
participants of the experimental group from January 2 to January 31, 2019, adding up to 8 sessions in total for each participant. Each session involved a 40-minute one-on-one sandplay therapy session with the therapist. The therapist also spent 20 minutes in discussion with the participant's parents. Group 2 was the control group that took the same pretest and posttest as the experimental group but did not participate in sandplay therapy.

In the first session, a briefing was given to the participant and the participant's parents on the basics features of the study, including its structure (how the study will be performed, length and venue), privacy measures, its objective and other details. The participants and their caregivers gave written consent for filming and photo-taking during the sessions. Table 1 presents the characteristics of the sample population.

\section{Research Design}

The study includes a pretest and posttest designed to verify the effectiveness of sandplay therapy in reducing academic stress and improving academic self-efficiency of Korean-Chinese children in China. Sandplay therapy is the independent variable, and changes in academic stress and self-efficiency represent the dependent variables. A pretest was administered to each participant before the initiation of sandplay therapy sessions, and an identical posttest was administered after all sessions were concluded.

\section{Measurement Tools}

\section{1) Measurement of academic stress}

To measure changes in academic stress levels, an academic stress measurement test developed by Mi-hyang Oh and Seong-moon Cheon (1984) and modified by Hyo-jin Kim (2010) was used. The test comprised of 75 question items that examine academic factors of stress, relationship-based factors of stress and academic stress symptoms. Under academic factors of stress, 7 items were related to academic grades, 11 were related to class time and 9 were related to studying. Under relationship-based factors of stress, 7 items were related to student-teacher relationships, 3 were related to family relationships and 9 were related to peer 
Journal of Symbols \& Sandplay Therapy, Vol.10 No.2.

Table 1. Personal characteristics of participants in experimental and control groups

\begin{tabular}{|c|c|c|c|c|c|c|c|}
\hline Group & Participant & Age & Gender & Group & Participant & Age & Gender \\
\hline \multirow{24}{*}{$\begin{array}{l}\text { Experimental } \\
\qquad \begin{array}{c}\text { Group } \\
(n=24)\end{array}\end{array}$} & A & 13 & F & \multirow{24}{*}{$\begin{array}{l}\text { Control } \\
\text { Group } \\
(n=24)\end{array}$} & A & 13 & M \\
\hline & B & 12 & $\mathrm{M}$ & & B & 12 & M \\
\hline & $\mathrm{C}$ & 13 & M & & $\mathrm{C}$ & 13 & $\mathrm{~F}$ \\
\hline & $\mathrm{D}$ & 12 & F & & $\mathrm{D}$ & 11 & F \\
\hline & E & 12 & F & & $\mathrm{E}$ & 11 & F \\
\hline & $\mathrm{F}$ & 11 & $\mathrm{M}$ & & F & 9 & F \\
\hline & G & 13 & $\mathrm{M}$ & & G & 10 & M \\
\hline & $\mathrm{H}$ & 11 & $\mathrm{M}$ & & $\mathrm{H}$ & 13 & $\mathrm{~F}$ \\
\hline & I & 13 & M & & I & 12 & M \\
\hline & $\mathrm{J}$ & 13 & F & & $\mathrm{J}$ & 13 & M \\
\hline & K & 10 & M & & $\mathrm{K}$ & 11 & M \\
\hline & $\mathrm{L}$ & 12 & F & & $\mathrm{L}$ & 12 & M \\
\hline & M & 12 & $\mathrm{~F}$ & & M & 12 & $\mathrm{~F}$ \\
\hline & $\mathrm{N}$ & 13 & $\mathrm{M}$ & & $\mathrm{N}$ & 11 & $\mathrm{~F}$ \\
\hline & $\mathrm{O}$ & 12 & F & & $\mathrm{O}$ & 13 & $\mathrm{~F}$ \\
\hline & $\mathrm{P}$ & 13 & F & & $\mathrm{P}$ & 13 & M \\
\hline & Q & 12 & M & & Q & 12 & $\mathrm{~F}$ \\
\hline & $\mathrm{R}$ & 10 & M & & $\mathrm{R}$ & 10 & F \\
\hline & S & 9 & M & & S & 10 & $\mathrm{~F}$ \\
\hline & $\mathrm{T}$ & 10 & M & & $\mathrm{T}$ & 12 & M \\
\hline & $\mathrm{U}$ & 13 & F & & $\mathrm{U}$ & 13 & F \\
\hline & $\mathrm{V}$ & 11 & M & & $\mathrm{V}$ & 13 & M \\
\hline & W & 10 & M & & W & 9 & M \\
\hline & $X$ & 8 & $\mathrm{M}$ & & $\mathrm{X}$ & 10 & $\mathrm{~F}$ \\
\hline
\end{tabular}

relationships. For stress symptoms, 4 items were related to physiological symptoms, 12 were related to psychological symptoms and 5 were related to behavioral symptoms. A 5-point Likert scale was applied for all question items, with 1 representing "strong negative" and 5 representing "strong positive." The total score for academic stress ranges from 75 to 375 points 
Table 2. Test items for academic stress and reliability coefficient

\begin{tabular}{|c|c|c|c|}
\hline & Sub-factor & Item Number & $\begin{array}{l}\text { Number } \\
\text { of Items }\end{array}$ \\
\hline \multirow{4}{*}{ Academic Factors } & Academic Grades & $1,7,14,20,27,39,43$ & 7 \\
\hline & Testing & $2,8,15,21,28,34,40,53$ & 8 \\
\hline & Class Time & $3,9,16,22,29,35,41,45,46,48,49$ & 11 \\
\hline & Studying & $4,10,17,23,30,36,37,42,44$ & 9 \\
\hline \multirow{3}{*}{$\begin{array}{l}\text { Relationship-based } \\
\text { Factors }\end{array}$} & Student-teacher Relationships & $5,11,18,24,31,51,54$ & 7 \\
\hline & Family Relationships & $6,12,25$ & 3 \\
\hline & Peer Relationships & $13,19,26,32,33,38,47,50,52$ & 9 \\
\hline \multirow{3}{*}{$\begin{array}{l}\text { Academic Stress } \\
\text { Symptoms }\end{array}$} & Physiological Symptoms & $57,64,65,75$ & 4 \\
\hline & Psychological Symptoms & $\begin{array}{c}55,56,59,58,61,63,66,67 \\
69,70,72,74\end{array}$ & 12 \\
\hline & Behavioral Symptoms & $60,62,68,71,73$ & 5 \\
\hline \multicolumn{3}{|c|}{ Total Number of Items } & 75 \\
\hline
\end{tabular}

and is the sum of scores for academic stress perception and stress symptoms. Higher scores indicate higher levels of academic stress. The overall reliability level based on an internal consistency estimate using Cronbach's alpha was .95. Reliability levels based on an internal consistency estimate using Cronbach's alpha for the academic factors of stress, relationship-based factors of stress and stress symptoms were $.88, .91$ and .84 , respectively. A breakdown of the test items is presented in Table 2.

\section{2) Measurement of academic self-efficiency}

To measure the academic self-efficiency of participating Korean-Chinese children, a verified academic self-efficiency test developed by Ah-young Kim and In-young Park (2001) was used. The test comprised of 28 question items, with 8 items related to self-confidence, 10 related to self-control efficiency and 10 to preferred task difficulty. A 5-point Likert scale was applied for all question items, with 1 representing "strong negative," 2 representing "negative," 3 representing "neutral," 4 representing "positive" and 5 representing "strong positive." 
Journal of Symbols \& Sandplay Therapy, Vol.10 No.2.

Responses for questions with negative wording were converted accordingly. Higher scores indicate higher levels of academic self-efficiency. The overall reliability level based on an internal consistency estimate using Cronbach's alpha was .94. The reliability levels based on an internal consistency estimate using Cronbach's alpha for the sub-factors of self-confidence, preferred task difficulty and self-control efficiency were .91, .84 and .85, respectively. A breakdown of the test items is presented in Table 3.

Table 3. Test items for academic self-efficiency and reliability coefficient

\begin{tabular}{ccc}
\hline Sub-factor & Number of Items & Item Number \\
\hline Self-confidence & 8 & $5^{*}, 8^{*}, 11^{*}, 14^{*}, 17^{*}, 18,20^{*}, 23$ \\
\hline Preferred Task Difficulty & 10 & $1,4,7,10,13,16^{*}, 19^{*}, 22,25,2$ \\
\hline Self-control Efficiency & 10 & $2,3,6,9,12,15,21,24,26^{*}, 27$ \\
\hline
\end{tabular}

*Score-converted items

\section{Research Procedure}

\section{1) Pretest and posttest}

A pretest was administered to the experimental and control groups to measure levels of academic stress and academic self-efficiency. After conducting sandplay therapy with only the experimental group, an identical posttest was administered to the participants of both groups.

\section{2) Sandplay therapy}

Each participant from the experimental group attended sandplay therapy sessions twice a week, from January 2 to January 31, 2019, for a total of 8 sessions. During each session, 40 minutes were spent on sandplay therapy, and 20 minutes were allocated to a discussion between the therapist and the participant's parents. Prior notice was given to the participants regarding the recording, filming and photo-taking of the participant's behaviors and stories that are displayed during sandplay, and consent forms were filled out. 


\section{Data analysis}

A quantitative analysis of the test results was carried out to verify the effectiveness of sandplay therapy in reducing academic stress and enhancing academic self-efficiency of Korean-Chinese children in China.

As a privacy measure, quantitative data collected from participants were coded. The SPSS 23.0 program was used for statistical processing, and a t-test was performed to verify the homogeneity of the experimental and control groups. A t-test was also administered to verify the significance of changes in academic stress and academic self-efficiency before and after sandplay therapy.

\section{Result And Interpretation}

\section{Effectiveness of Sandplay Therapy on Academic Stress of Korean-Chinese Children}

A pretest and posttest were administered to the experimental and control groups before and after sandplay therapy to measure the effects of sandplay therapy on academic stress levels of Korean-Chinese children living in China.

Among the sub-factors of academic stress, scores for academic factors decreased after sandplay therapy $(M=119.25)$ compared to before sandplay therapy $(M=125.5)$ for the experimental group. Scores for academic factors increased after sandplay therapy ( $M=132.66)$ compared to before sandplay therapy $(\mathrm{M}=125.2)$ for the control group. A verification of the difference between the posttest scores for academic factors for the experimental and control groups revealed statistical significance $(\mathrm{t}=-3.22, \mathrm{p}<.01)$. Thus, it may be inferred that sandplay therapy reduces academic stress that come from academic factors.

Scores for relationship-based factors decreased after sandplay therapy $(M=67.83)$

compared to before sandplay therapy $(\mathrm{M}=71.00)$ for the experimental group. Scores for relationship-based factors increased after sandplay therapy $(\mathrm{M}=73.50)$ compared to before 
Journal of Symbols \& Sandplay Therapy, Vol.10 No.2.

Table 4. Comparison of Academic Stress Scores between Experimental and Control Groups

\begin{tabular}{|c|c|c|c|c|}
\hline \multirow[t]{2}{*}{ Categories } & & $\begin{array}{c}\text { Experimental } \\
\text { Group }(n=24)\end{array}$ & $\begin{array}{l}\text { Control Group } \\
\qquad(n=24)\end{array}$ & \multirow[t]{2}{*}{$t$} \\
\hline & & $\mathrm{M}(\mathrm{SD})$ & $\mathrm{M}(\mathrm{SD})$ & \\
\hline \multirow{2}{*}{ Academic Factors } & Pretest & $125.5(13.57)$ & $125.2(13.34)$ & 0.75 \\
\hline & Posttest & $119.25(13.75)$ & $132.66(15.10)$ & $-3.22^{* *}$ \\
\hline \multirow{2}{*}{ Relationship-based Factors } & Pretest & $71.00(6.14)$ & $71.29(6.09)$ & -0.17 \\
\hline & Posttest & $67.83(5.32)$ & $73.5(6.43)$ & $-3.33^{* *}$ \\
\hline \multirow{2}{*}{ Academic Stress Symptoms } & Pretest & 77.66(7.94) & $77.37(7.51)$ & 0.13 \\
\hline & Posttest & $74.08(7.48)$ & $79.95(8.27)$ & $-2.58^{*}$ \\
\hline \multirow{2}{*}{ Academic Stress Total } & Pretest & $274.16(26.31)$ & $273.87(25.51)$ & 0.04 \\
\hline & Posttest & $261.16(24.15)$ & $286.12(29.23)$ & $-3.22^{* *}$ \\
\hline
\end{tabular}

${ }^{*} p<.05{ }^{* *} p<.01{ }^{* * *} p<.001$

sandplay therapy $(M=71.29)$ for the control group. A verification of the difference between the posttest scores for relationship-based factors for the experimental and control groups revealed statistical significance $(\mathrm{t}=-3.33, \mathrm{p}<.01)$. Thus, it may be inferred that sandplay therapy reduces academic stress that come from relationship-based factors.

Scores for academic stress symptoms decreased after sandplay therapy $(M=74.08)$ compared to before sandplay therapy $(M=77.66)$ for the experimental group. Scores for academic stress symptoms increased after sandplay therapy $(\mathrm{M}=79.95)$ compared to before sandplay therapy $(M=77.37)$ for the control group. A verification of the difference between posttest scores for academic stress symptoms for the experimental and control groups revealed statistical significance $(\mathrm{t}=-2.58, \mathrm{p}<.05)$. Thus, it may be inferred that sandplay therapy reduces academic stress symptoms of Korean-Chinese children.

The total score for academic stress decreased after sandplay therapy $(M=261.16)$ compared to before sandplay therapy $(\mathrm{M}=274.16)$ for the experimental group. The total score for the control group increased somewhat after sandplay therapy $(M=286.12)$ compared to before sandplay therapy $(M=273.87)$. A verification of the difference between total posttest 
scores for the experimental and control groups revealed statistical significance $(\mathrm{t}=-3.22, \mathrm{p}<.01)$.

The findings indicate that sandplay therapy is effective in reducing the overall level of academic stress for Korean-Chinese children in China.

\section{Effectiveness of Sandplay Therapy on Academic Self-efficiency of Korean-Chinese Children}

A pretest and posttest were administered to the experimental and control groups before and after sandplay therapy to measure the effects of sandplay therapy on the academic self-efficiency of Korean-Chinese children living in China.

Table 5. Comparison of academic self-efficiency scores between experimental and control groups

\begin{tabular}{|c|c|c|c|c|}
\hline \multicolumn{2}{|l|}{ Categories } & \multirow{2}{*}{$\begin{array}{c}\text { Experimental } \\
\text { Group }(n=24) \\
\mathrm{M}(\mathrm{SD})\end{array}$} & \multirow{2}{*}{$\begin{array}{c}\text { Control Group } \\
\qquad \begin{array}{c}(n=24) \\
\mathrm{M}(\mathrm{SD})\end{array}\end{array}$} & \multirow[t]{2}{*}{$t$} \\
\hline & & & & \\
\hline \multirow{2}{*}{ Self-confidence } & Pretest & $19.04(2.42)$ & $18.95(2.33)$ & 0.12 \\
\hline & Posttest & $25.08(4.79)$ & $18.79(2.01)$ & $5.89^{* * *}$ \\
\hline \multirow{2}{*}{ Preferred Task Difficulty } & Pretest & $25.87(3.05)$ & $25.37(3.89)$ & 0.50 \\
\hline & Posttest & $29.16(4.20)$ & $25.25(4.37)$ & $3.16^{*}$ \\
\hline \multirow{2}{*}{ Self-control Efficiency } & Pretest & $23.83(3.34)$ & $24.04(3.50)$ & -0.21 \\
\hline & Posttest & $28.08(4.69)$ & $23.62(4.50)$ & $3.35^{*}$ \\
\hline \multirow[t]{2}{*}{ Academic Self-efficiency Total } & Pretest & $68.75(5.32)$ & $68.37(5.06)$ & 0.25 \\
\hline & Posttest & $84.66(10.29)$ & $67.66(6.17)$ & $6.94^{* * *}$ \\
\hline
\end{tabular}

${ }^{*} p<.05{ }^{* *} p<.01{ }^{* * *} p<.001$

Among the sub-factors of academic self-efficiency, scores for self-confidence increased after sandplay therapy $(M=25.08)$ compared to before sandplay therapy $(M=19.04)$ for the experimental group. Scores for self-confidence decreased after sandplay therapy $(\mathrm{M}=18.79)$ compared to before sandplay therapy $(M=18.95)$ for the control group. A verification of the 
Journal of Symbols \& Sandplay Therapy, Vol.10 No.2.

difference between the posttest scores for self-confidence for the experimental and control groups revealed statistical significance $(\mathrm{t}=5.89, \mathrm{p}<.001)$. Thus, it may be inferred that sandplay therapy enhances self-confidence of Korean-Chinese children living in China.

Scores for preferred task difficulty increased after sandplay therapy $(M=29.16)$ compared to before sandplay therapy $(\mathbf{M}=25.87)$ for the experimental group. Scores for preferred task difficulty decreased after sandplay therapy $(M=25.25)$ compared to before sandplay therapy $(M=25.37)$ for the control group. A verification of the difference between the posttest scores for preferred task difficulty for the experimental and control groups revealed statistical significance $(t=3.16, p<.05)$. Thus, it may be inferred that sandplay therapy enhances the preferred task difficulty of Korean-Chinese children living in China.

Scores for self-control efficiency increased after sandplay therapy $(M=28.08)$ compared to before sandplay therapy $(\mathrm{M}=23.83)$ for the experimental group. Scores for self-control efficiency decreased after sandplay therapy $(M=23.62)$ compared to before sandplay therapy $(\mathrm{M}=24.04)$ for the control group. A verification of the difference between the posttest scores for self-control efficiency for the experimental and control groups revealed statistical significance $(t=3.354, p<.05)$. Thus, it may be inferred that sandplay therapy enhances the self-control efficiency of Korean-Chinese children living in China.

The total score for academic self-efficiency increased after sandplay therapy $(M=84.66)$ compared to before sandplay therapy $(M=68.75)$ for the experimental group. The total score for the control group decreased somewhat after sandplay therapy $(\mathrm{M}=67.66)$ compared to before sandplay therapy $(M=68.37)$. A verification of the difference between total posttest scores for the experimental and control groups revealed statistical significance $(t=6.94, p<.01)$.

The findings indicate that sandplay therapy is effective in enhancing overall academic self-efficiency of Korean-Chinese children in China. 


\section{Discussion And Conclusion}

\section{Summary and Discussion}

This study was designed to verify the effects of sandplay therapy on levels of academic stress and academic self-efficiency of Korean-Chinese children living in and going to elementary school in China.

48 children with problematic behaviors related to academic stress and academic self-efficiency were recommended by their school homeroom teachers and members of the Yanbian Education Research Society to participate in the study. A pretest was administered to the participating children to measure levels of academic stress and academic self-efficiency. 24 of the participants were then assigned to the experimental group and took part in sandplay therapy. The other 24 participants were assigned to the control group. After the sandplay therapy sessions were over, a posttest was administered to both groups. Participants in the experimental group attended two sandplay therapy sessions each week from January 2 to January 31, 2019, totaling eight sessions per participant. The different behaviors, stories and responses of the participants demonstrated during sandplay therapy were recorded and filmed. Identical pretests and posttests were conducted before and after sandplay therapy to verify the effectiveness of sandplay therapy. Participants of the control group did not participate in sandplay therapy.

The results of the study are as follows:

First, there was a significant difference in the academic and relationship-based factors of academic stress and academic stress symptoms for the experimental group before and after sandplay therapy. No significant difference was found for the control group. Therefore, it may be inferred that sandplay therapy is effective in reducing the effects of academic and relationship-based factors of academic stress and academic stress symptoms for Korean-Chinese children in China.

Second, there was a significant difference in terms of self-confidence, preferred task difficulty and self-control efficiency for the experimental group before and after sandplay 
Journal of Symbols \& Sandplay Therapy, Vol.10 No.2.

therapy. No significant difference was found for the control group. Therefore, it may be inferred that sandplay therapy is effective in enhancing the self-confidence, preferred task difficulty and self-control efficiency sub-factors of academic self-efficiency.

\section{Limitations and Suggestions}

Based on the findings of the study, the following is a discussion on the limitations of this study and suggestions for other studies going forward.

First, although the study was conducted on a number of Korean-Chinese children living in China, the findings are not sufficient to be generalized to the entire population of Korean-Chinese children in China. More studies with more population samples will be needed for this.

Second, although the study has found that sandplay therapy is effective in reducing levels of academic stress and enhancing academic self-efficiency of Korean-Chinese children in China, it should be backed up with more studies that look into other psychological factors.

Third, there were cases in this study in which homeroom teachers had a negative effect on levels of academic stress and academic self-efficiency of the participating children. By inviting homeroom teachers to participate in the study and sharing with them an understanding of the participating child and applied therapy, even more productive results may be expected.

Fourth, the study was conducted during a school vacation period and was thus bound by a limited timeframe. Because sandplay sessions were scheduled twice a week, participants did not have enough time for inner preparation in between sessions. For future studies, more time should be given to ensure that participants come into each session with sufficient inner preparation.

Nevertheless, the study holds significance in that it demonstrates the effectiveness of sandplay therapy in reducing academic stress and enhancing academic self-efficiency of Korean-Chinese children in China, particularly as the current number of studies examining the effects of this therapeutic intervention on the emotional difficulties of Korean-Chinese children is far from enough.

To gain a better understanding of the psychological and emotional difficulties of 
Korean-Chinese children in China and help them adjust to the surrounding society and culture, future studies may supplement the limitations of this study by carrying out the therapeutic intervention on participants of a more diverse range of gender and age.

\section{References}

Bandura, A. (1997). Self-efficacy: The exercise of control. New York: W.H. Freemanand Company.

Cottrell, A. (1997). A dictionary of world mythology. Seoul: Kkachigeulbang.

Erina, L, M, Wendy, Samter., \& Seth, J, G. (2005). Academic Stress, Supportive Communication, and Health. Communication Education, 54(4), 365-372.

Eom, M-S. (2013). Effects of samulnori-based music therapy on academic stress and self-efficacy of 4th graders. Daegu University. Graduate School of Education. Master's Thesis.

Kim, D-A. (2005). The effect of group music activities on children's stress reduction. Graduate School of Music Therapy, Sookmyung Women's University. Master's thesis.

Kim, I-B. (2018). Actively seeking the path of education in the global era. Yanbian Daily.

Kim, I-B. (2018). What kind of problem is kindergarten becoming like elementary school? Yanbian Daily.

Kim, S-O. (2003). Effects of cognitive-behavioral academic stress coping training on elementary school students' academic stress and academic self-efficacy. Graduate School of Education, Daegu University of Education. Master's thesis,

Kim, Y-J. (2017). The mediating effects of stress response behavior on the relationship between academic self-efficacy and career development of elementary school students. Graduate School of Music Therapy, Sookmyung Women's University. Master's thesis.

Ko, K-M. (2012). A study on relationship between the elememntary gifted's academic self-efficacy and self-determination. Graduate School of Education, Daegu University. Master's Thesis.

Lee, A-K. (2009). A study on factors of stress and stress coping styles according to self-efficacy: Focus on high school students. Sangmyung University Graduate School. 
Journal of Symbols \& Sandplay Therapy, Vol.10 No.2.

Master's thesis.

Lee, Y-R, Jang, M-K, \& Shim, J-H. (2018). The Effectiveness of Group Sandplay Therapy on Quality of Peer Relationship and Behavioral Problems of Korean-Chinese Children in China. Symbols and Sandplay Therapy, 9(2). 61-80.

Liu, Y., \& Lu, Z. (2011). The Chinese high school student's stress in the school and academic achievement. Educational Psychology, 31(1), 27-35.

Shin, H-S, \& Jeong, J-J. (2006). The effects of cognitive-behavioral academic stress coping and training on elementary school academic stress and exam anxiety. The Journal of the Korean Association on Developmental Diabilities. 10(1), 73-87.

Steinhardt, L, F. (2013). On becoming a Jungian sandplay therapist: The healing spirit of sandplay in nature and in therapy. London \& Philadelphia: Jessica Kingsley Publishers. 